\title{
Venturamides A and B: Antimalarial Constituents of the Panamanian Marine Cyanobacterium Oscillatoria sp.
}

\author{
Roger G. Linington, José Gonzalez, Luis-David Ureña, Luz I. Romero, Eduardo Ortega-
}

Barría, and William H. Gerwick

\section{Supporting Information}

S1. ${ }^{1} \mathrm{H}$ NMR spectrum of venturamide A (1) recorded in $\mathrm{CDCl}_{3}$ at $400 \mathrm{MHz}$.

S2. ${ }^{13} \mathrm{C}$ NMR spectrum of venturamide $\mathrm{A}(\mathbf{1})$ recorded in $\mathrm{CDCl}_{3}$ at $100 \mathrm{MHz}$

S3. ${ }^{1} \mathrm{H}$ NMR spectrum of venturamide $\mathrm{B}(2)$ recorded in $\mathrm{CDCl}_{3}$ at $400 \mathrm{MHz}$. 4

S4. ${ }^{13} \mathrm{C}$ NMR spectrum of venturamide $\mathrm{B}(2)$ recorded in $\mathrm{CDCl}_{3}$ at $100 \mathrm{MHz}$.

S5. HPLC traces of Marfey's derivatives for $\mathbf{1}$. 6

S6. HPLC traces of Marfey's derivatives for 2

S7. Photomicrographs of source Oscillatoria sp 8

S8. Details of biological assays 
S1. ${ }^{1} \mathrm{H}$ NMR spectrum of venturamide $\mathrm{A}(1)$ recorded in $\mathrm{CDCl}_{3}$ at $400 \mathrm{MHz}$

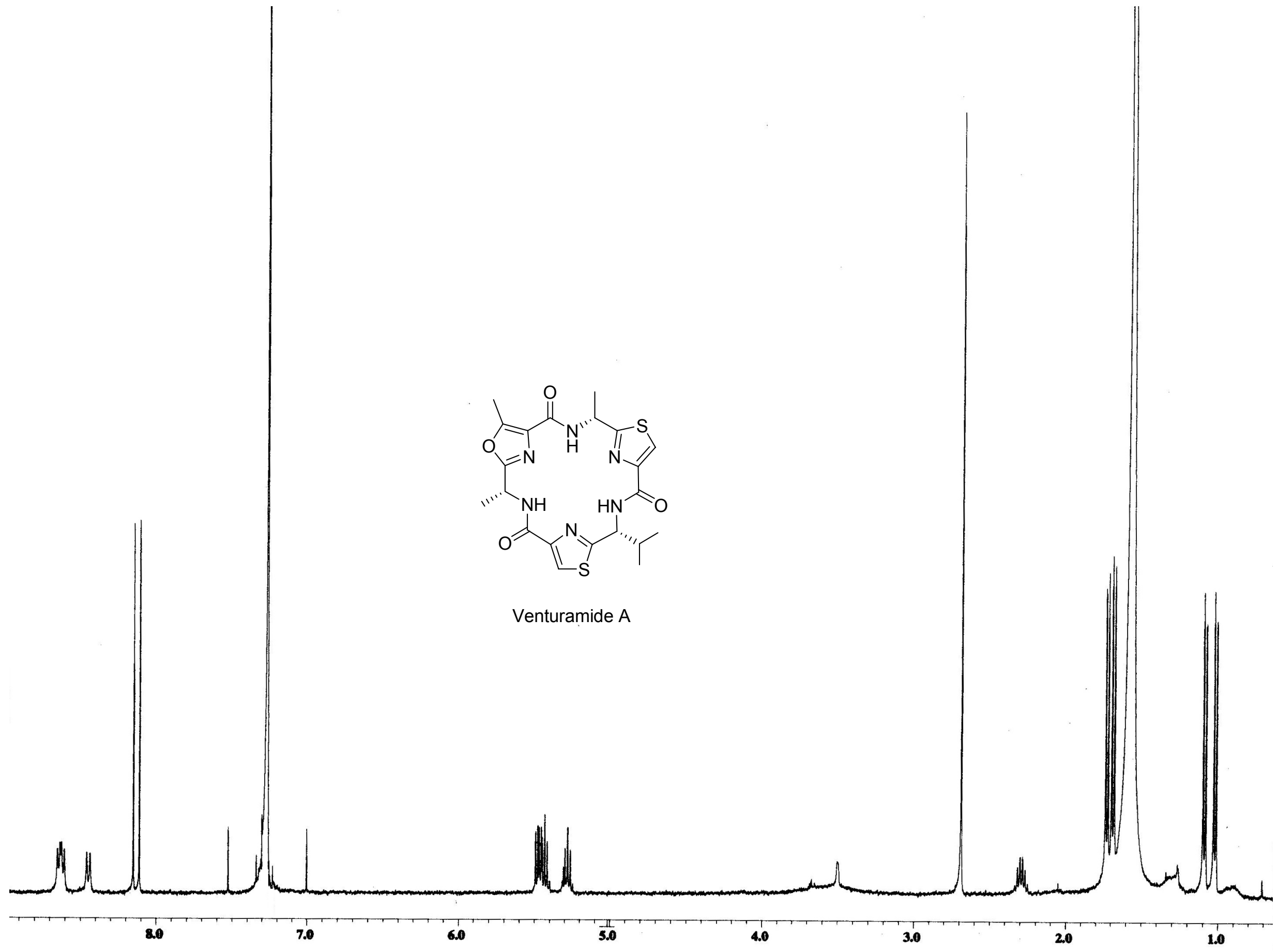


S2. ${ }^{13} \mathrm{C}$ NMR spectrum of venturamide $\mathrm{A}(1)$ recorded in $\mathrm{CDCl}_{3}$ at $100 \mathrm{MHz}$

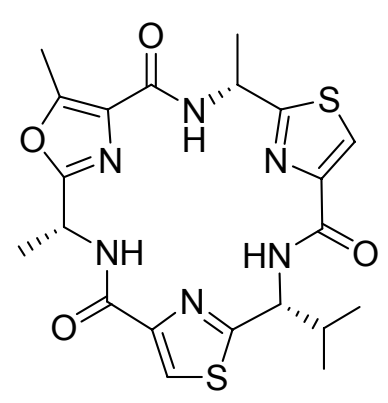

Venturamide A

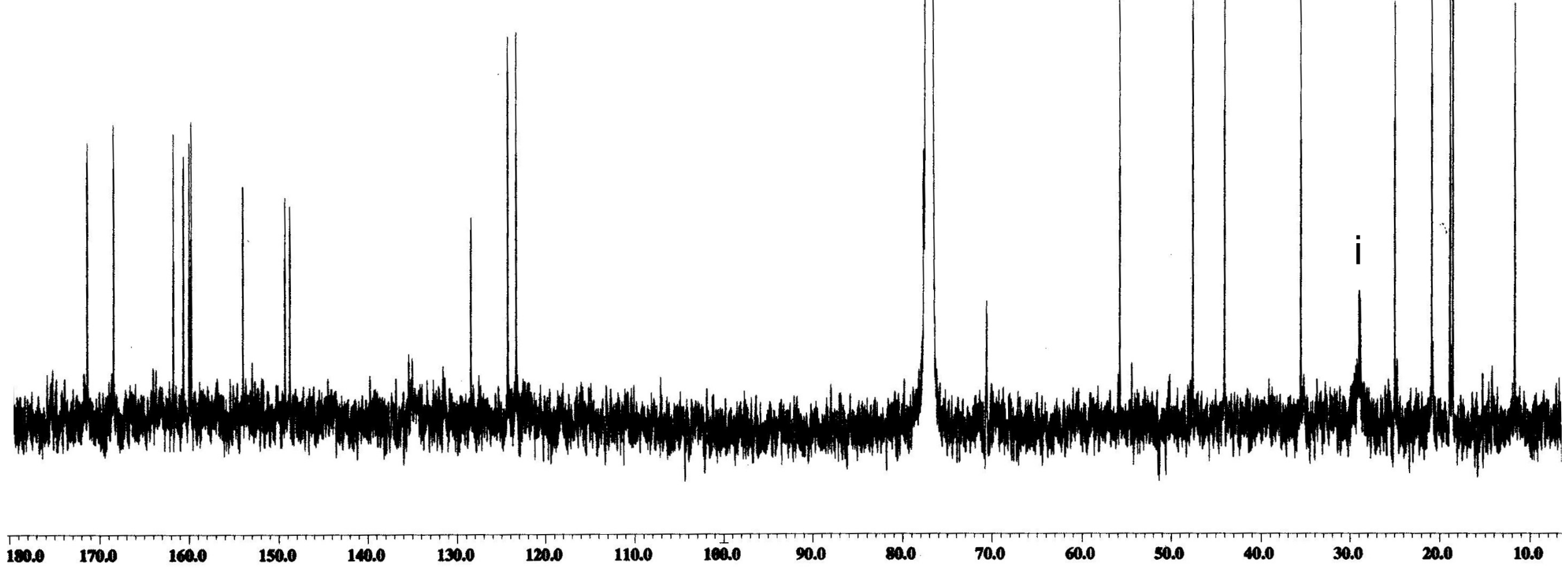


S3. ${ }^{1} \mathrm{H}$ NMR spectrum of venturamide $\mathrm{B}(2)$ recorded in $\mathrm{CDCl}_{3}$ at $400 \mathrm{MHz}$

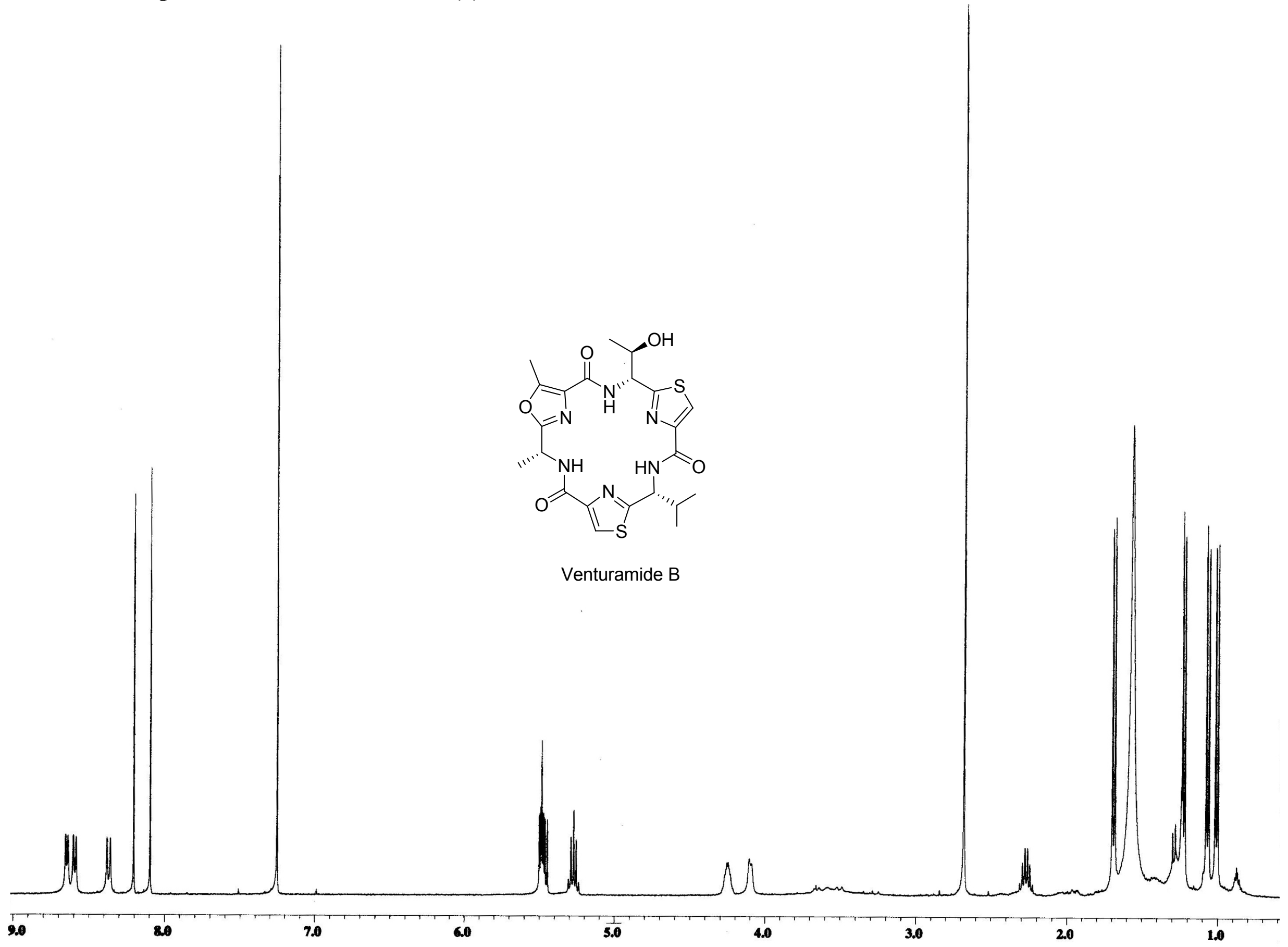


S4. ${ }^{13} \mathrm{C}$ NMR spectrum of venturamide $\mathrm{B}(2)$ recorded in $\mathrm{CDCl}_{3}$ at $100 \mathrm{MHz}$

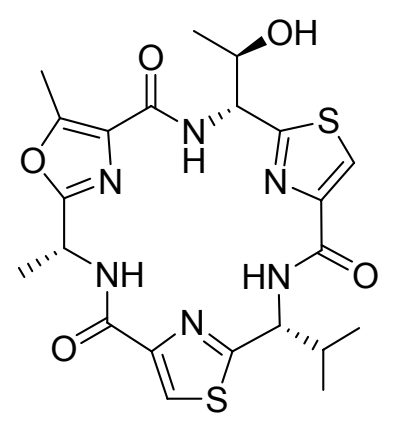

Venturamide B

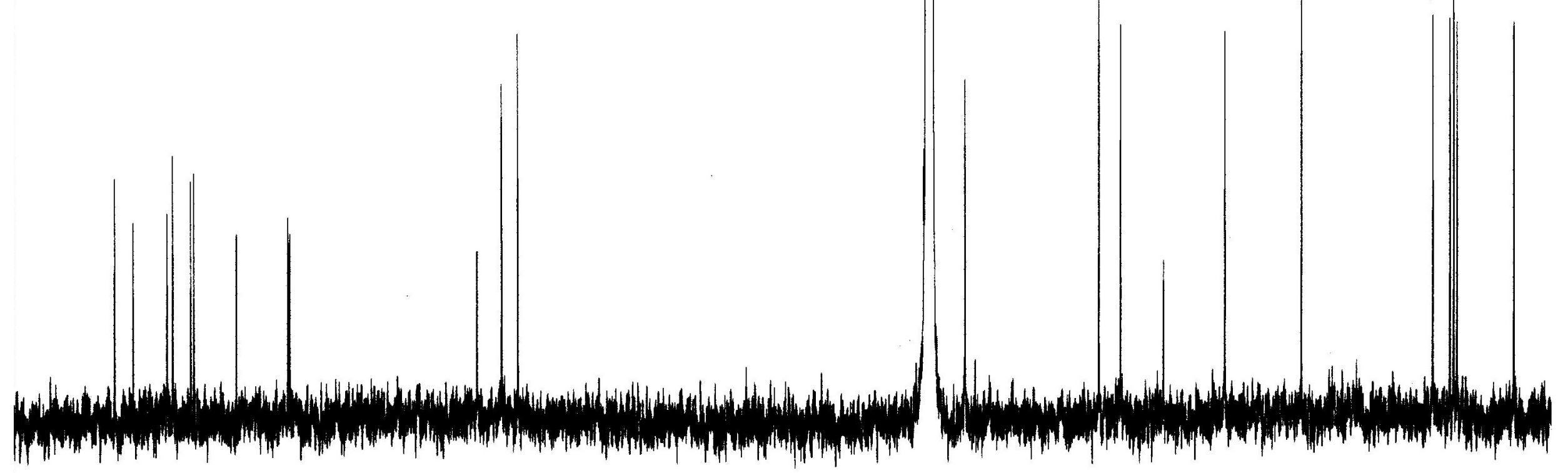




\section{S5. HPLC traces of Marfey's derivatives for 1}

Marfey's analysis of the direct hydrolysis products of $\mathbf{1}$

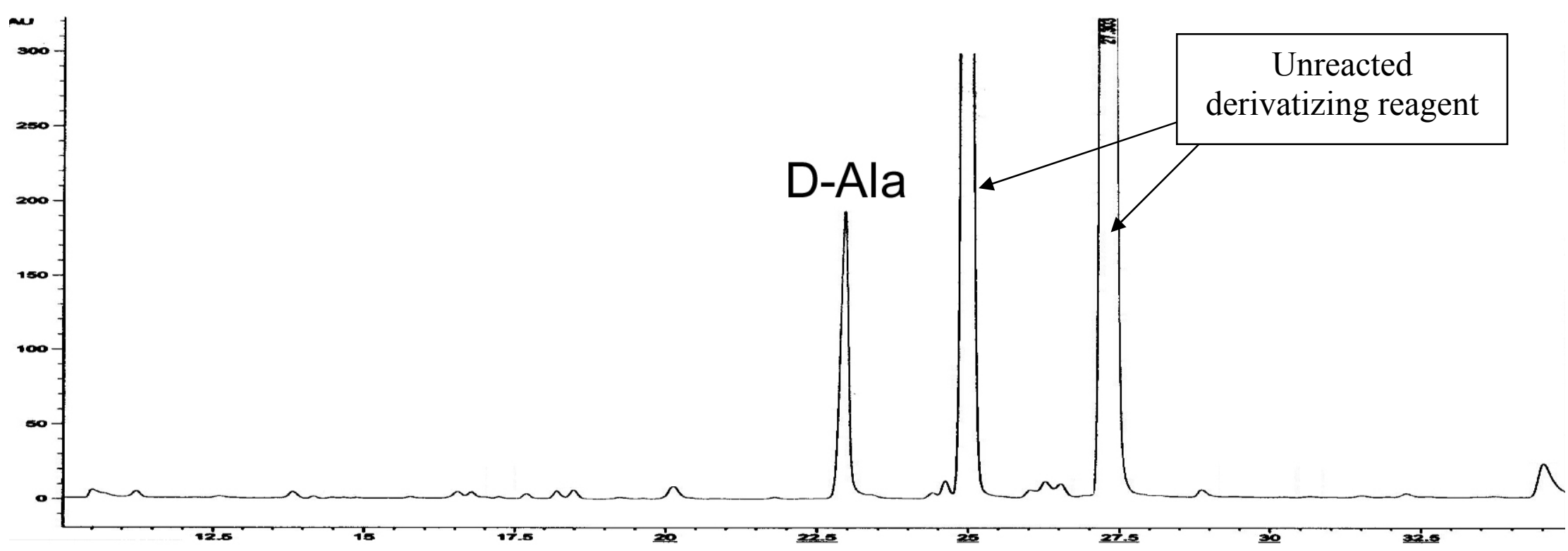

Marfey's analysis of the hydrolysis products of $\mathbf{1}$ post-ozonolysis

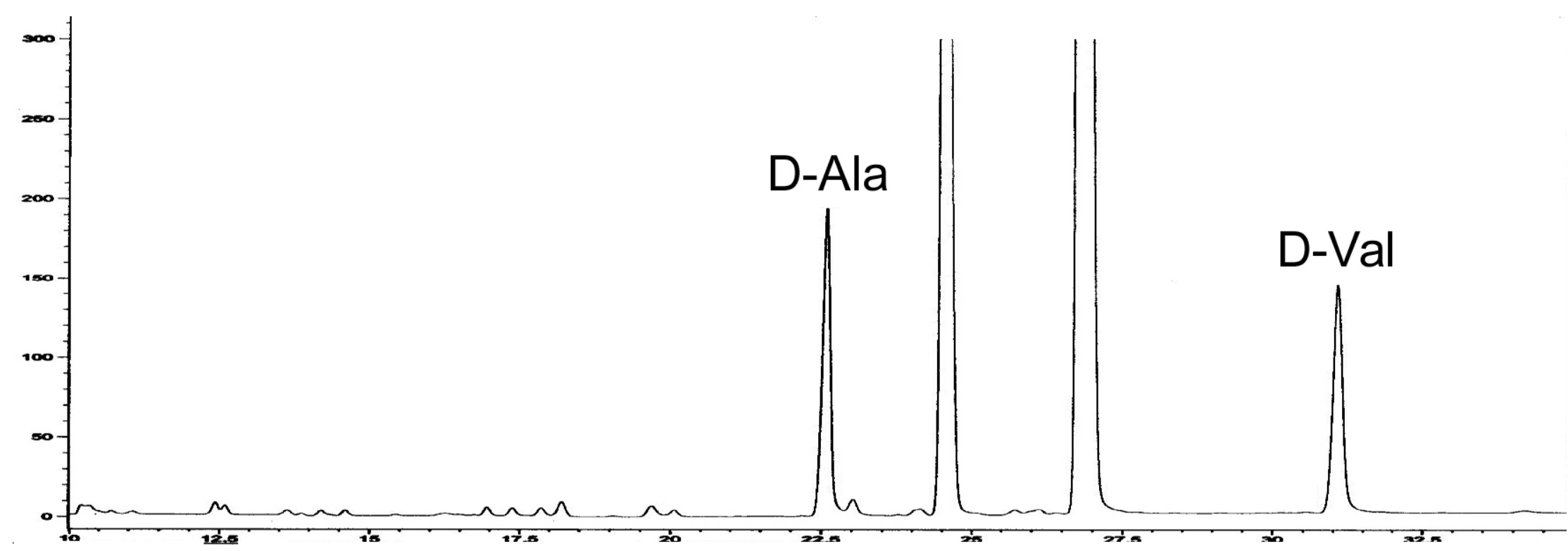




\section{S6. HPLC traces of Marfey's derivatives for 2}

Marfey's analysis of the direct hydrolysis products of $\mathbf{2}$

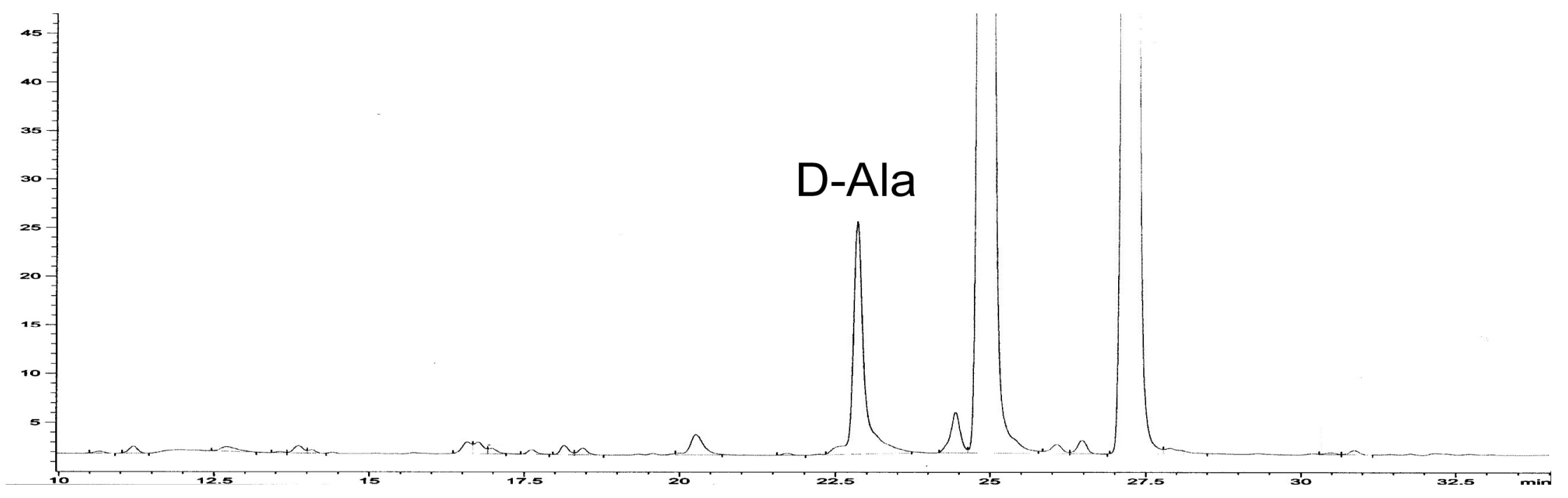

Marfey's analysis of the hydrolysis products of $\mathbf{2}$ post-ozonolysis

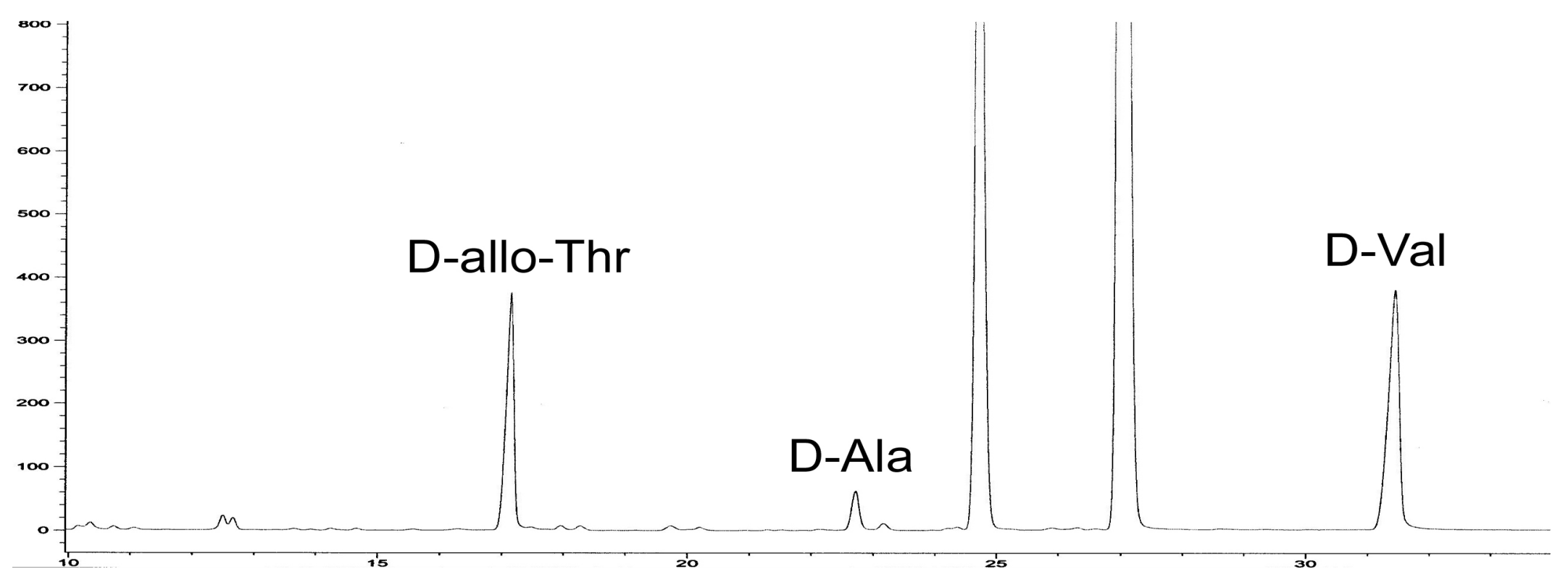


S7. Photomicrographs of source Oscillatoria sp.
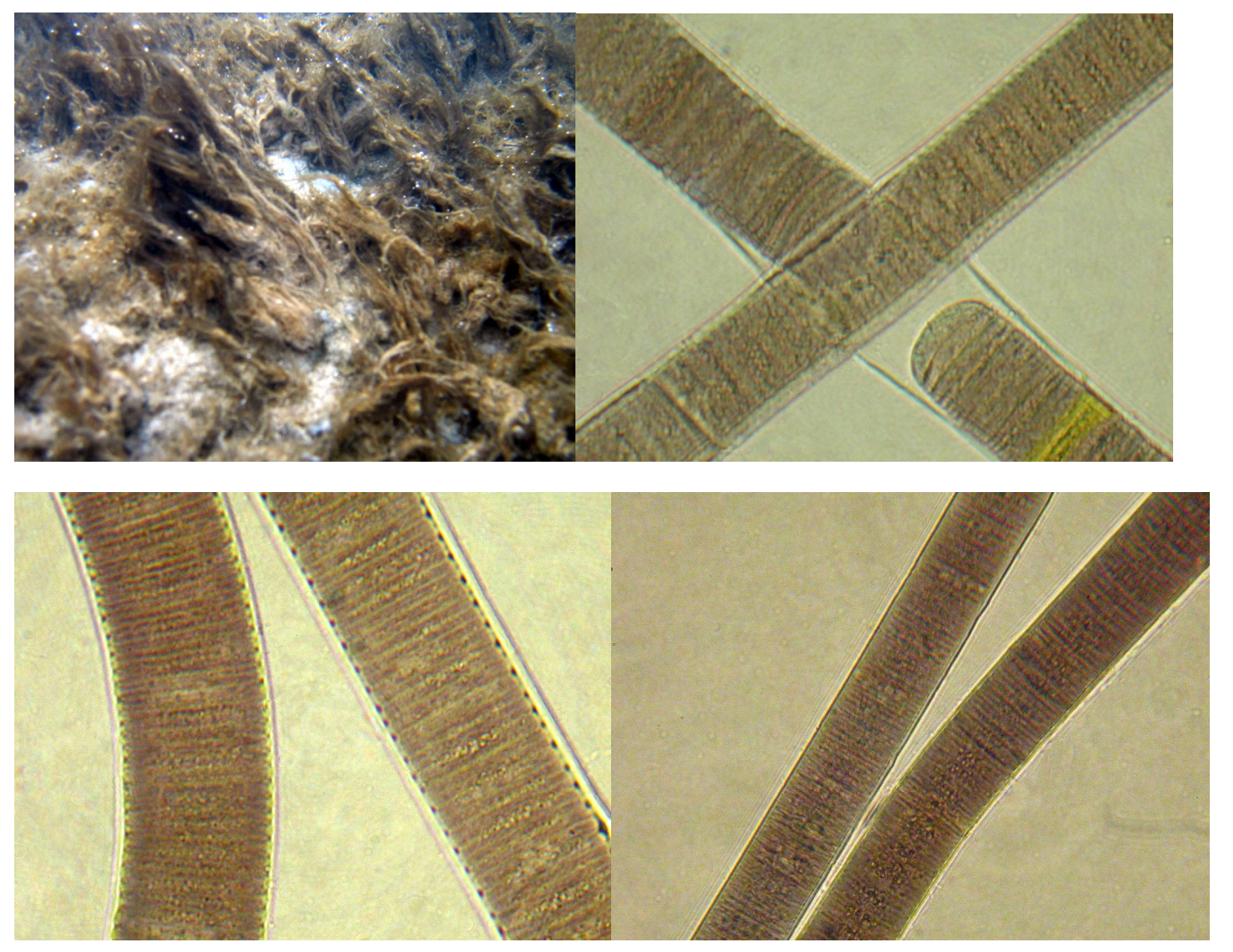


\section{S8. Details of biological assays}

Trypanosoma cruzi bioassay. The recombinant Tulahuen clone C4 of Trypanosoma cruzi that expresses $\beta$-galactosidase $(\beta-\mathrm{Gal})$ as a reporter enzyme was used in this assay (1). The method was based on the growth inhibition effect of test samples on amastigote, the intracellular form of the parasite. The resulting colour from the cleavage of chlorophenol red- $\beta$-D-galactoside $(\mathrm{CPRG})$ by $\beta$-Gal, expressed by the parasite, was measured with a $570 \mathrm{~nm}$ filter. The inhibition concentration of $50 \%\left(\mathrm{IC}_{50}\right)$ was calculated by comparing with an untreated control. Nifurtimox was used as control drug and exerted an $\mathrm{IC}_{50}$ value of $5 \mu \mathrm{g} / \mathrm{mL}$. All assays were conducted at $37^{\circ} \mathrm{C}$ under an atmosphere of 5\% C02/95\% air mixture

Malaria Bioassay. Antiplasmodial activity was determined in a chloroquine-resistant P. falciparum strain (W2 Indochina) utilizing a novel microfluorimetric assay to measure the inhibition of the parasite growth based on the detection of the parasitic DNA by intercalation with PicoGreen (2). The $\mathrm{IC}_{50}$ values were calculated from relative fluorescence units as compared with untreated controls. Chloroquine was used as control drug and exerted an $\mathrm{IC}_{50}$ value of $100 \mathrm{nM}$. The parasites were maintained at $2 \%$ haematocrit in flat-bottom flasks (75 mL) with RMPI 1640 medium (GibcoBRL) supplemented with $10 \%$ human serum.

Leishmania bioassay. The study used a fluorimetric Leishmania donovani (LD1S/MHOM/SD/00-strain 1S), amastigote assay adapted from a novel micromethod (2) and employed in our laboratory (3) to measure inhibition of the parasite growth based on the detection of parasitic DNA by intercalation with PicoGreen. Briefly, 25,000 amastigotes were co-incubated with the test substances at $32{ }^{\circ} \mathrm{C}$ in a $\mathrm{CO} 2$ free 
atmosphere during $72 \mathrm{~h}$. The relative fluorescence units (RFU) were quantified with a fluorescence microplate reader (FLx 800; Bio-Tek Instruments, Inc., Winooski, VT) at $485 / 20 \mathrm{~nm}$ excitation and $528 / 20 \mathrm{~nm}$ emission filters. The $\mathrm{IC}_{50}$ values were calculated from relative fluorescence units as compared with untreated controls. Amphotericin-B was used as control drug and had an $\mathrm{IC}_{50}$ value of $80 \mathrm{ng} / \mathrm{ml}$.

Cytotoxicity bioassay. Vero cells adhering to 96-well plates were used to evaluate the toxicity of the assayed compounds after $72 \mathrm{~h}$ co-incubation at $37^{\circ}$ in a $\mathrm{CO}_{2}$ atmosphere. Cell viability was evaluated on the basis of reduction of 3-(4,5-dimethylthiazol-2-yl)2,5-diphenyltetrazolium bromide (MTT, Sigma) by the mitochondrial dehydrogenase by the alive cells (4). Optical reading were measured in a Benchmark plate reader (BIORAD) employing a 570-nm test wavelength and a 650-nm reference filter.

(1) Buckner, F. S.; Verlinde, C. L. M. J.; La Flamme, A. C.; Van Voorhis, W. C. Antimicrob. Agents Chemother. 1996, 40, 2592-2597.

(2) Corbett, Y.; Herrera, L.; Gonzalez, J.; Cubilla, L.; Capson, T. L.; Coley, P. D.; Kursar, T. A.; Romero, L. I.; Ortega-Barria, E. Am. J. Trop. Med. Hyg. 2004, 70, $119-$ 124.

(3) Calderon, A.; Romero, L. I.; Ortega-Barra, E.; Brun, R.; Correa, M. A.; Gupta, M. P. Panama Pharm. Biol. 2006, 44, 1-16.

(4) Van de Loosdrecht, A. A.; Beelen, R. H. J. ; Ossenkoppele, G. J.; Broekhoven, M. G.; Langenhuijsen, M. M. A. C. J. Immunol. Methods, 1994 174, 311-320. 